\title{
Wnt1 overexpression associated with tumor proliferation and a poor prognosis in non-small cell lung cancer patients
}

\author{
TAKASHI NAKASHIMA ${ }^{1}$, DAGE LIU ${ }^{1}$, JUN NAKANO ${ }^{1}$, SHINYA ISHIKAWA ${ }^{1}$, \\ HIROYASU YOKOMISE ${ }^{1}$, MASAKI UENO ${ }^{2}$, KYUICHI KADOTA ${ }^{3}$ and CHENG-LONG HUANG ${ }^{1}$ \\ Departments of ${ }^{1}$ General Thoracic Surgery, Breast and Endocrinological Surgery, ${ }^{2}$ Pathology and Host Defense and \\ ${ }^{3}$ Pathology, Faculty of Medicine, Kagawa University, 1750-1 Miki-cho, Kita-gun, Kagawa 761-0793, Japan
}

Received August 27, 2007; Accepted October 18, 2007

\begin{abstract}
The Wnt family genes encode multifunctional signaling glycoproteins that are involved in the regulation of a wide variety of normal and pathological processes including tumorigenesis. In order to clarify the clinical significance of the intratumoral Wnt 1 expression in non-small cell lung cancer (NSCLC), we performed an immunohistochemical study on the Wnt1 expression in NSCLCs in relation to the tumor proliferation. The intratumoral $\mathrm{Wnt} 1$ protein expression appeared in a cytoplasmic staining pattern. Of the 151 NSCLCs studied, 61 carcinomas $(40.4 \%)$ were Wnt1positive. Regarding the tumor biology of the intratumoral Wnt 1 expression, the Ki-67 proliferation index was significantly higher in Wnt1-positive than in Wnt1-negative tumors $(\mathrm{P}=0.0062)$. Furthermore, regarding the expression of $\mathrm{c}-\mathrm{Myc}$, one of the proliferation-regulating Wnt targets, the percentage of c-Myc-positive tumor cells was significantly higher in Wnt1-positive than in Wnt1-negative tumors $(\mathrm{P}=0.0019)$. The Ki-67 proliferation index was significantly higher in c-Myc-positive than in c-Myc-negative tumors $(\mathrm{P}=0.0239)$. The overall survival was significantly lower in patients with Wnt1-positive NSCLCs than in patients with Wnt1-negative NSCLCs $(\mathrm{P}=0.0003)$. A Cox regression analysis demonstrated that the Wnt1 status was a significant prognostic factor for NSCLC patients (hazard ratio 1.983; $\mathrm{P}=0.0061$ ). Our results revealed that the Wnt 1 overexpression affects the tumor proliferation in NSCLCs, partly via the upregulation of c-Myc.
\end{abstract}

\section{Introduction}

Non-small cell lung cancer (NSCLC) is one of the most common cancers and the major cause of cancer-related death in North America, Europe and Japan (1). Therefore, it is important to clarify the mechanism of its tumor biology in

Correspondence to: Dr Cheng-long Huang, The Department of General Thoracic Surgery, Breast and Endocrinological Surgery, Faculty of Medicine, Kagawa University, 1750-1 Miki-cho, Kita-gun, Kagawa 761-0793, Japan

E-mail: chuang@kms.ac.jp

Key words: Wnt1, c-Myc, proliferation, prognosis, lung cancer order to improve the clinical outcome of NSCLC patients (2). Studies on the molecular biology of human cancers have revealed that many molecules affect the progression of malignant tumors. The activation of oncogenes or the inactivation of tumor suppressor genes could initially cause carcinogenesis (3). Then, many molecules associated with angiogenesis or metastasis could produce more aggressive malignant tumors during the subsequent tumor progression $(4,5)$. Considering these facts, the clarification of the mechanism of tumor progression in NSCLCs could potentially lead to the development of a new strategy of treatments for NSCLC patients.

Among the many molecules associated with tumorigenesis, the Wnt family genes are frequently upregulated in many human cancers (6-9). The Wnt family genes encode multifunctional signaling glycoproteins that are involved in the regulation of a wide variety of normal and pathological processes, including embryogenesis, differentiation and tumorigenesis (10-12). In addition, a previous study showed that transfection of the metastatic suppressor gene MRP$1 / C D 9$ can downregulate the expression of various Wnts, including Wnt1 and Wnt5a (13). However, the clinical significance of these Wnt expression levels in human cancers is still unclear. Therefore, an immunohistochemical clinical investigation was conducted on the intratumoral Wnt1 expression in NSCLCs in relation to tumor proliferation. The expression of c-Myc, one of the proliferation-regulating target genes of the canonical Wnt/ß-catenin pathway was evaluated (14).

\section{Materials and methods}

Clinical characteristics of the patients. NSCLC patients who underwent surgery at the Faculty of Medicine, Kagawa University from January 1993 to February 2001 were studied. This study was approved by the institutional review board of Kagawa University (14-7, a clinical study of biological markers in NSCLCs) and signed informed consent was obtained from each patient. Tumor-node-metastasis (TNM) staging designations were made according to the postsurgical pathological international staging system. Since advanced stage lung cancer (stage IV) involved several ill-defined factors and had distant metastases, such patients were excluded from this study. In total, 151 patients with lung cancer up to 
stage III, comprising 88 patients with adenocarcinomas, 53 patients with squamous cell carcinomas, and 10 patients with large cell carcinomas, were investigated. The patients' clinical records and histopathological diagnoses were fully documented. This report includes follow-up data as of October 31, 2006.

Immunohistochemistry for Wnt1, c-Myc and Ki-67. We used a rabbit polyclonal antibody for Wnt1 (H-89, Santa Cruz Biotechnology Inc., Santa Cruz, CA, USA) diluted at 1:200, a mouse monoclonal antibody for c-Myc (9E10, Santa Cruz) diluted at 1:100, and a mouse monoclonal antibody for Ki-67 (MIB-1, Dako, Glostrup, Denmark) diluted at 1:40. Formalinfixed paraffin-embedded tissue was cut in 4- $\mu \mathrm{m}$ sections and mounted on poly-L-lysine-coated slides. Sections were deparaffinized and rehydrated. The slides were then heated in a microwave for $10 \mathrm{~min}$ in a $10-\mu \mathrm{mol} / \mathrm{l}$ citrate buffer solution at $\mathrm{pH} 6.0$ and then cooled to room temperature. After quenching the endogenous peroxidase activity with $0.3 \% \mathrm{H}_{2} \mathrm{O}_{2}$ (in absolute methanol) for $30 \mathrm{~min}$, the sections were treated for $2 \mathrm{~h}$ at room temperature with $5 \%$ bovine serum albumin. Duplicate sections were then incubated overnight with the primary specific antibodies against Wnt1, c-Myc and Ki-67, respectively. The slides were then incubated for $1 \mathrm{~h}$ with biotinylated anti-rabbit IgG (Vector Laboratories Inc., Burlingame, CA) for Wnt1, and biotinylated anti-mouse IgG (Vector) for c-Myc and Ki-67. The sections were incubated with the avidin-biotin-peroxidase complex (Vector) for $1 \mathrm{~h}$, and antibody binding was visualized with 3,3'-diaminobenzidine tetrahydrochloride. The sections were then lightly counterstained with Mayer's hematoxylin. Sections of resected lung tumors known to express Wnt1 or c-Myc were used as positive controls for immunohistochemical staining. Sections incubated with normal rabbit $\operatorname{IgG}$ served as negative reaction controls for staining of Wnt1, and sections incubated with normal mouse IgG served as negative reaction controls for staining of c-Myc.

All the immunostained sections were evaluated by two authors (T.N. and M.U.) who had no knowledge of the patients' clinical status. For protein expression of Wnt1 and c-Myc, the proportion of staining tumor cells in each selected field was determined by counting individual tumor cells at a high magnification. In cases with multiple areas of low intensity that occurred during evaluation of immunostaining, five areas were selected at random and scored. One random field was selected in sections where all staining appeared intense. At least 200 tumor cells were scored per x40 field. The percentage of carcinoma cells with positive staining for $\mathrm{Ki}-67$ in a given specimen was scored as the Ki-67 proliferation index (15).

Statistical analysis. Since the distributions of three variables, including the percentage of Wnt1-positive tumor cells $(\mathrm{P}=0.8853)$, the percentage of c-Myc-positive tumor cells $(\mathrm{P}=0.7008)$, and the Ki-67 proliferation index $(\mathrm{P}=0.8583)$, all showed normal distributions (Kolmogorov-Smirnov analysis), the statistical differences regarding these variables in relation to several clinical and pathological parameters were assessed by the t-test, and analysis of variance with the Bonferroni/ Dunn test. As the Wnt1 protein expression cutoff line of $50 \%$ demonstrated the greatest significance in relation to the Ki-67 proliferation index, the sample was classified as Wnt1-positive when $\geq 50 \%$ of the carcinoma cells in a given specimen were positively stained for Wnt 1 . Since the c-Myc protein expression cutoff line of $30 \%$ demonstrated the most significance in relation to the Ki-67 proliferation index, the sample was classified as c-Myc-positive when $\geq 30 \%$ of the carcinoma cells in a given specimen were positively stained for c-Myc. Overall survival was defined as the time from the treatment initiation (surgical resection, chemotherapy, or radiation) to the date of death from any cause. The KaplanMeier method was used to estimate the probability of overall survival as a function of time, and differences in the survival of subgroups of patients were compared by using Mantel's log-rank test. A multivariate analysis was performed using the Cox regression model to study the effects of different variables on survival. All P-values were based on two-tailed statistical analysis, and a P-value $<0.05$ was considered to indicate a statistical significance.

\section{Results}

Intratumoral Wnt1 expression in NSCLCs. The intratumoral Wnt1 protein expression appeared in the form of a cytoplasmic staining pattern (Fig. 1A). The percentage of Wnt1-positive tumor cells varied greatly among NSCLCs (mean, $42.0 \pm 28.4 \%$, Table I). Of the 151 NSCLCs studied, 61 carcinomas (40.4\%) were Wnt 1-positive. Regarding tumor histology, the percentage of Wnt1-positive tumor cells was $40.5 \pm 27.8 \%$ in adenocarcinomas and $46.9 \pm 28.2 \%$ in squamous cell carcinomas. There was no difference in the intratumoral Wnt1 expression according to tumor histology. In addition, there was no difference in the intratumoral Wnt 1 expression according to tumor status, nodal status or tumor differentiation.

Tumor proliferation of NSCLCs in relation to Wnt1 status. To investigate the tumor proliferation of NSCLCs, we evaluated the Ki-67 proliferation index (Fig. 1B). Of the 151 NSCLCs studied, the Ki-67 proliferation index varied greatly (mean, $44.3 \pm 30.2 \%$ ). Regarding the tumor proliferation in relation to the Wnt1 status, the Ki-67 proliferation index was $52.4 \pm 30.6 \%$ in Wnt1-positive tumors and $38.8 \pm 28.8 \%$ in Wnt1-negative tumors. The Ki-67 proliferation index was significantly higher in Wnt1-positive tumors than in Wnt1-negative tumors $(\mathrm{P}=0.0062$, Fig. 2).

c-Myc expression in relation to Wht1 status. We then studied the intratumoral expression of c-Myc, one of proliferationregulating Wnt1 targets. The percentage of c-Myc-positive tumor cells varied greatly among the 151 NSCLCs (mean, $36.5 \pm 27.3 \%$, Table I and Fig. 1C). Regarding the c-Myc expression in relation to the Wnt1 status, the percentage of c-Myc-positive tumor cells was $44.7 \pm 26.2 \%$ in Wnt1-positive tumors and $30.8 \pm 26.7 \%$ in Wnt 1 -negative tumors. The percentage of c-Myc-positive tumor cells was significantly higher in Wnt1-positive tumors than in Wnt1-negative tumors ( $\mathrm{P}=0.0019$, Fig. 3).

Clinical significance of $c-M y c$ expression in NSCLCs. Of the 151 tumors studied, 85 carcinomas $(56.3 \%)$ were c-Myc- 

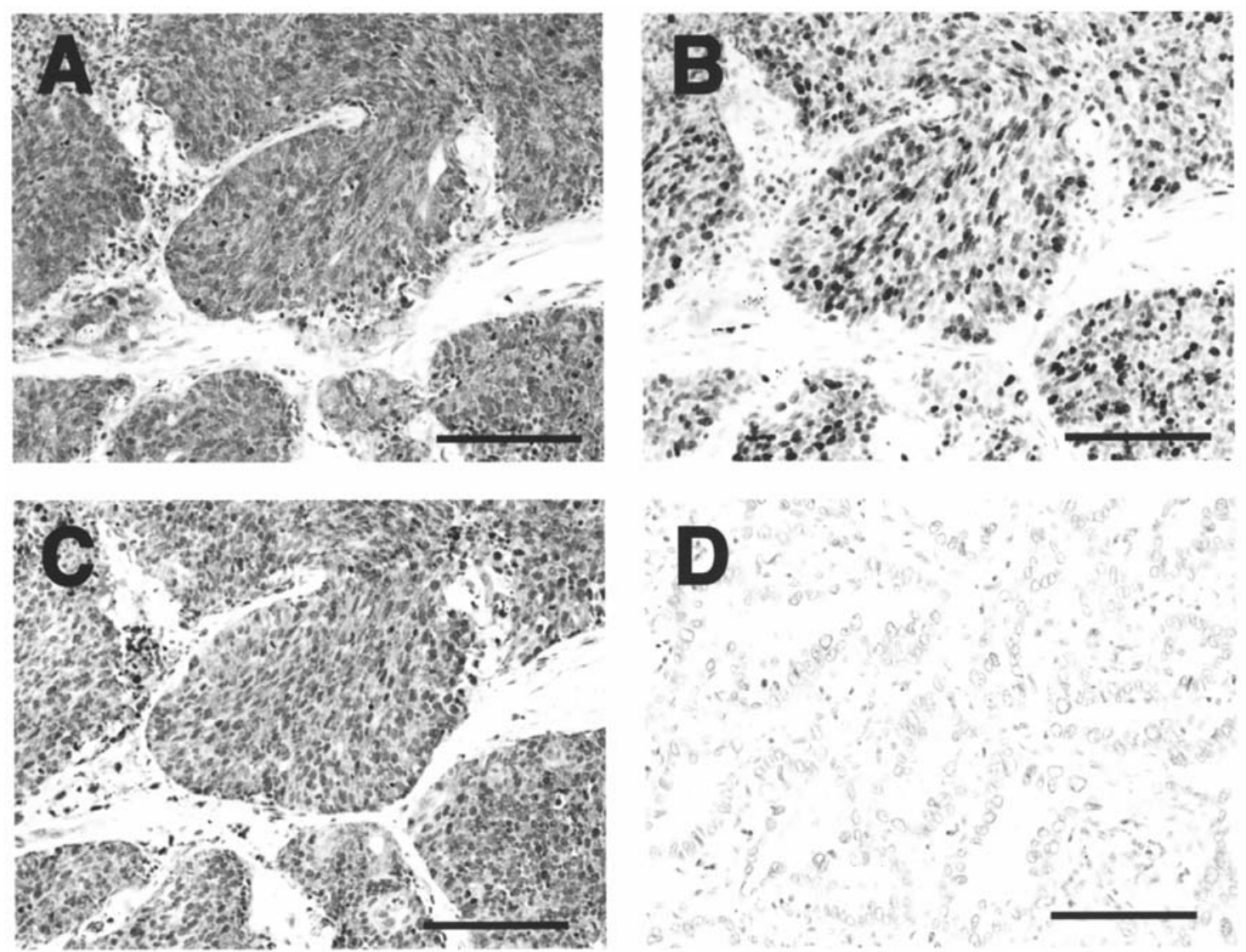

Figure 1. Immunohistochemical staining of human non-small cell lung cancer tissues by the avidin-biotin-peroxidase complex procedure. A carcinoma with (A) positive expression of Wnt1, (B) high Ki-67 index, and (C) positive expression of c-Myc. (D) A carcinoma with negative expression of Wnt1. Bar, $100 \mu \mathrm{m}$.

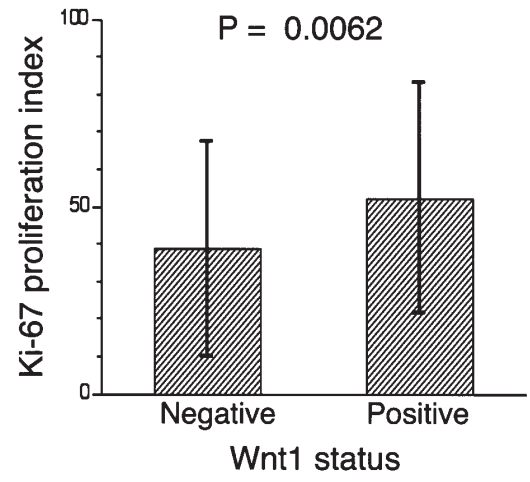

Figure 2. Ki-67 proliferation index in relation to Wnt1 status.

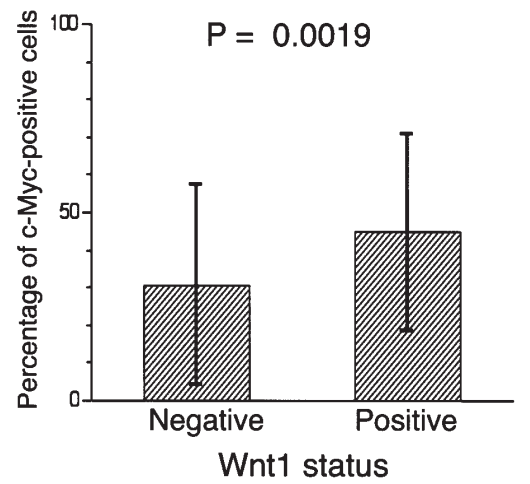

Figure 3. c-Myc expression in relation to Wnt1 status.

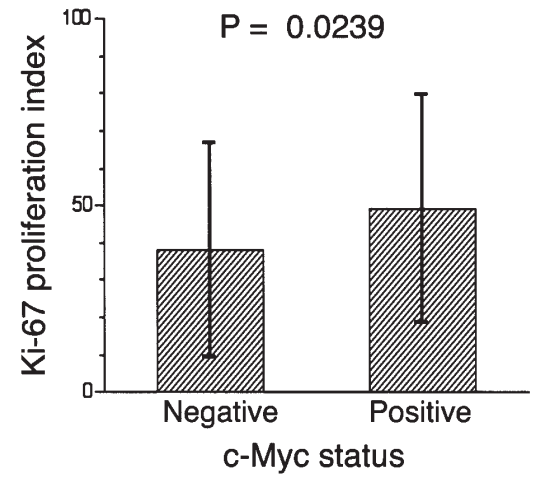

Figure 4. Ki-67 proliferation index in relation to c-Myc status.

positive (Table I). Regarding tumor histology, the percentage of c-Myc-positive tumor cells was $33.2 \pm 26.4 \%$ in adenocarcinomas and $42.5 \pm 28.3 \%$ in squamous cell carcinomas. There was no difference in the c-Myc expression according to tumor histology. In addition, there was no difference in the intratumoral c-Myc expression according to tumor status, nodal status or tumor differentiation.

Regarding the tumor proliferation in relation to the $\mathrm{c}-\mathrm{Myc}$ status, the Ki-67 proliferation index was $49.2 \pm 30.6 \%$ in cMyc-positive tumors and $38.0 \pm 28.7 \%$ in c-Myc-negative tumors. The Ki-67 proliferation index was significantly higher in c-Myc-positive than in c-Myc-negative tumors $(\mathrm{P}=0.0239$, Fig. 4). 
Table I. Distribution of Wnt1 and c-Myc status in 151 NSCLC patients.

\begin{tabular}{|c|c|c|c|c|c|c|c|}
\hline \multirow[b]{2}{*}{ Characteristics } & \multirow[b]{2}{*}{$\mathrm{n}$} & \multicolumn{3}{|c|}{ Wnt1 status } & \multicolumn{3}{|c|}{ c-Myc status } \\
\hline & & $\%$ & P-value & Positive & $\%$ & P-value & Positive \\
\hline \multicolumn{8}{|l|}{ Smoking } \\
\hline Non-smoker & 57 & $46.1 \pm 27.4$ & 0.1595 & 26 & $37.8 \pm 27.7$ & 0.6378 & 34 \\
\hline Smoker & 94 & $39.4 \pm 28.8$ & & 35 & $35.6 \pm 27.2$ & & 51 \\
\hline \multicolumn{8}{|l|}{ Tumor status } \\
\hline $\mathrm{T} 1, \mathrm{~T} 2$ & 111 & $41.3 \pm 27.7$ & 0.6197 & 43 & $35.6 \pm 27.5$ & 0.5376 & 59 \\
\hline $\mathrm{T} 3, \mathrm{~T} 4$ & 40 & $43.9 \pm 30.6$ & & 18 & $38.8 \pm 27.1$ & & 26 \\
\hline \multicolumn{8}{|l|}{ Nodal status } \\
\hline No & 105 & $39.4 \pm 29.0$ & 0.0993 & 37 & $35.2 \pm 26.1$ & 0.4093 & 57 \\
\hline $\mathrm{N} 1, \mathrm{~N} 2, \mathrm{~N} 3$ & 46 & $47.7 \pm 26.6$ & & 24 & $39.2 \pm 30.0$ & & 28 \\
\hline \multicolumn{8}{|l|}{ Pathological stage } \\
\hline Stage I & 84 & $39.2 \pm 27.6$ & 0.1662 & 30 & $34.4 \pm 26.5$ & 0.5771 & 42 \\
\hline Stage II & 16 & $37.2 \pm 31.6$ & & 4 & $37.8 \pm 33.2$ & & 9 \\
\hline Stage III & 51 & $48.0 \pm 28.3$ & & 27 & $39.4 \pm 26.9$ & & 34 \\
\hline \multicolumn{8}{|l|}{ Differentiation } \\
\hline Well & 55 & $40.5 \pm 27.0$ & 0.7738 & 18 & $31.3 \pm 26.2$ & 0.0790 & 27 \\
\hline Moderately & 58 & $44.1 \pm 28.1$ & & 26 & $43.4 \pm 26.9$ & & 39 \\
\hline Poorly & 38 & $40.9 \pm 31.3$ & & 17 & $33.4 \pm 28.0$ & & 19 \\
\hline \multicolumn{8}{|l|}{ Histology } \\
\hline Adenocarcinoma & 88 & $40.5 \pm 27.8$ & 0.1412 & 32 & $33.2 \pm 26.4$ & 0.1313 & 45 \\
\hline Squamous cell carcinoma & 53 & $46.9 \pm 28.2$ & & 27 & $42.5 \pm 28.3$ & & 34 \\
\hline Large cell carcinoma & 10 & $29.0 \pm 32.8$ & & 2 & $33.0 \pm 27.1$ & & 6 \\
\hline Total number of patients & 151 & $42.0 \pm 28.4$ & & 61 & $36.5 \pm 27.3$ & & 85 \\
\hline
\end{tabular}

Table II. Multivariate regression analysis in predicting survival of NSCLC patients.

\begin{tabular}{lccc}
\hline Variables & Hazard ratio & $95 \%$ CI & P-value \\
\hline Wnt1 status & 1.983 & $(1.216-3.236)$ & 0.0061 \\
Smoking & 0.945 & $(0.458-1.947)$ & 0.8775 \\
Gender & 0.762 & $(0.343-1.695)$ & 0.5056 \\
Tumor status & 1.407 & $(1.148-1.725)$ & 0.0010 \\
Nodal status & 1.578 & $(1.222-2.038)$ & 0.0005 \\
Differentiation & 1.311 & $(0.955-1.801)$ & 0.0937 \\
\hline
\end{tabular}

CI, confidence interval.

Overall survival of NSCLC patients in relation to Wnt1 status. The 5-year survival rate of 151 NSCLC patients stratified according to their Wnt 1 status is shown in Fig. 5A. Regarding Wnt1 status, the 5-year survival rate was $39.9 \%$ in patients with Wnt1-positive NSCLCs and $67.5 \%$ in patients with Wnt1-negative NSCLCs. The overall survival was significantly lower in patients with Wnt1-positive NSCLCs than in patients with Wnt1-negative NSCLCs $(\mathrm{P}=0.0003)$. Furthermore, regarding the c-Myc status, the overall survival was significantly lower in patients with c-Myc-positive NSCLCs than in patients with c-Myc-negative NSCLCs $(\mathrm{P}=0.0325$, Fig. 5B).

A multivariate analysis using the Cox regression model was performed in order to evaluate prognostic factors for
NSCLC patients, as shown in Table II. Three variables, Wnt1 status (hazard ratio 1.983; $\mathrm{P}=0.0061$ ), tumor status (hazard ratio $1.407 ; \mathrm{P}=0.0010$ ), and nodal status (hazard ratio 1.578 ; $\mathrm{P}=0.0005)$, were significant prognostic factors for NSCLC patients.

\section{Discussion}

The Wnt family is a large family of homologous but distinct genes, which have been highly conserved across species during evolution. The Wnt genes encode secreted cysteine-rich proteins with multidirectional biological functions via autocrine or paracrine routes (11). They are involved in the regulation of a wide variety of normal and pathological 
A

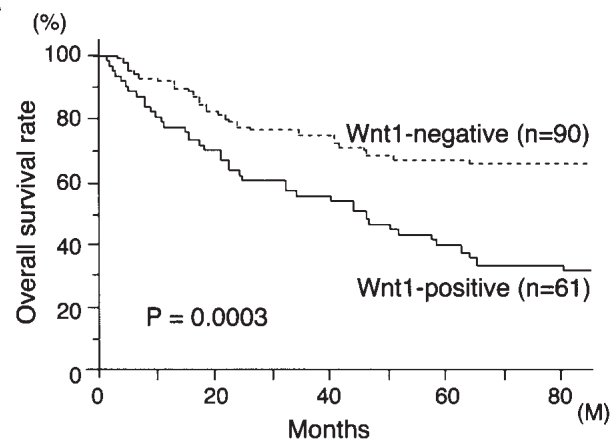

B

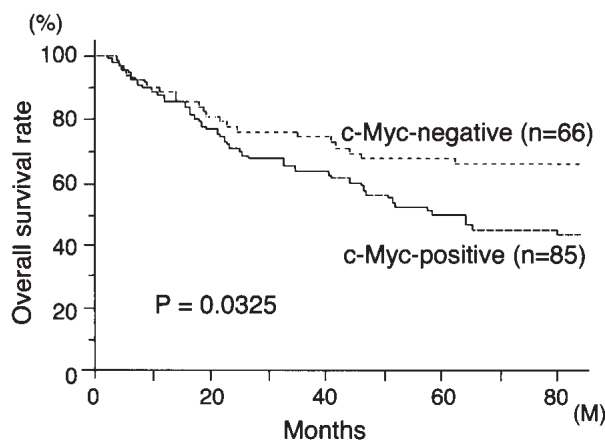

Figure 5. Overall survival in relation to Wnt1 status (A) and c-Myc status (B).

processes including tumorigenesis (10-12). The Wnt genes have been classified into functional groups with separate downstream signaling pathways $(16,17)$. Among them, Wnt1 stimulates the canonical Wnt/ß-catenin signaling pathway, which leads to changes in cell fate and/or cell transformation (18). The canonical Wnt/ß-catenin signaling pathway regulates the transcription of many Wnt-target genes with TCF/LEF1 motifs (19). As a result, the intratumoral Wnt1 expression could affect many biological functions through these Wnt-target genes.

Recent studies have revealed that the upregulation of Wnt1 frequently occurs in many human cancers $(6-8,20)$. However, the clinical significance of the Wnt1 expression in human cancers is still unclear. Therefore, we conducted a clinical study on the intratumoral Wnt1 expression in NSCLCs. Consequently, the present study demonstrated that the intratumoral Wnt1 expression was associated with tumor proliferation in NSCLCs. The tumor proliferation was significantly higher in Wnt1-positive than in Wnt1-negative tumors. In addition, the intratumoral Wnt1 status was a significant prognostic factor for NSCLC patients. A Cox regression analysis demonstrated that the hazard ratio associated with the Wnt1 status was higher than those of tumor status and nodal status in NSCLC patients. The present study is the first clinical report demonstrating the clinical significance of the Wnt1 overexpression in NSCLCs. A recent clinical study in oral squamous cell carcinomas also revealed that the Wnt 1 expression was associated with tumor proliferation (8). Experimental studies using cell lines have demonstrated that the canonical Wnt signaling pathway stimulates cell proliferation $(21,22)$. Furthermore, the Wnt inhibitory factor was reported to inhibit the proliferation of lung cancer cells (23).

The canonical Wnt/ß-catenin signaling pathway can affect various biological functions through the induction of many Wnt-target genes containing the TCF/LEF1 motifs (19). This fact makes the clinical significance of the Wnt signaling pathway rather confusing. Therefore, we performed an additional study on the intratumoral expression of c-Myc, one of the target genes of the canonical Wnt/ß-catenin pathway (14). c-Myc is a transcriptional factor that plays a role in cell proliferation, apoptosis and in the development of human cancers (24-26). Although the precise mechanism of c-Myc action is not yet fully understood, c-Myc is considered to be involved in growth control and cell cycle progression by stimulating and repressing the expression of cell cycle regulators. The c-Myc overexpression has been reported to promote the $\mathrm{G} 1$ to $\mathrm{S}$ transition by activating cyclinE/cdk2 complexes in lung cancer cells (26). Furthermore, experimental studies have also demonstrated that the downregulation of c-Myc can inhibit the proliferation of cell lines, including lung cancer cells $(27,28)$.

The present clinical study demonstrated the intratumoral c-Myc expression to be associated with the intratumoral Wnt1 expression in NSCLCs. The intratumoral c-Myc expression was significantly higher in Wnt1-positive than in Wnt1negative tumors. The intratumoral c-Myc expression was associated with tumor proliferation. The Ki-67 proliferation index was significantly higher in c-Myc-positive than in cMyc-negative tumors. In addition, the overall survival was significantly lower in patients with c-Myc-positive NSCLCs than in patients with c-Myc-negative NSCLCs. As a result, the present study demonstrated that the Wnt1 overexpression affects tumor proliferation through the induction of the cMyc expression, via autocrine or paracrine routes. A recent experimental study has also revealed that the Wnt signaling pathway contributes to c-Myc pro-mutagenic effects in cancer cell lines (22).

The overexpression of c-Myc has been reported in lung cancer cells and tumor samples $(29,30)$. In many clinical studies, including the present study, the c-Myc overexpression has been reported to be a factor of poor prognosis in cancer patients (31-33). Although the gene amplification of c-Myc frequently occurs in NSCLCs $(29,34)$, the present study revealed that the Wntl overexpression is another mechanism of the c-Myc overexpression. The present study is the first clinical report demonstrating the association between the Wnt1 expression and the c-Myc expression in NSCLCs. Previous clinical studies have suggested an association between the canonical $\mathrm{Wnt} / \mathrm{B}$-catenin signaling pathway and the c-Myc expression in human cancers $(35,36)$.

Regarding the activation of the canonical Wnt/ß-catenin signaling pathway, it is mainly caused by inactive mutations of the adenomatous polyposis coli gene or by activating mutations of the $\beta$-catenin gene in the development of colorectal carcinomas (37). However, previous clinical 
studies have revealed these mutations to be rare in NSCLCs $(38,39)$. In contrast, experimental studies using cell lines have demonstrated that the Wnt 1 expression is regulated by various molecules $(6,13,40)$. Therefore, the intratumoral Wnt 1 expression might be secondarily regulated in response to a range of changes of many molecules during tumor progression. As a result, the Wnt1 overexpression can produce more aggressive malignant tumors during progression.

In conclusion, the present study demonstrated that the overexpression of Wnt 1 was associated with tumor proliferation in NSCLCs and that its overexpression was a significant prognostic factor for NSCLC patients. Furthermore, the Wnt1 expression was associated with c-Myc expression, a proliferation-regulating Wnt target. These results suggest that the Wnt 1 overexpression affects tumor proliferation in NSCLC, partly via the upregulation of c-Myc. These results also indicate that the suppression of this pathway may be a potentially effective treatment for patients with Wnt1positive NSCLCs $(23,27,28)$. In addition, because the Wnt pathway can affect various biological functions through the induction of many Wnt-target genes, further studies on other Wnt targets are necessary in order to clarify its precise mechanisms in human cancers.

\section{Acknowledgements}

This study was supported by a Grant-in-Aid for Scientific Research from the Japanese Society for the Promotion of Science, grant no. 18390379 (C.H.).

\section{References}

1. Cersosimo RJ: Lung cancer: a review. Am J Health Syst Pharm 59: 611-642, 2002.

2. Huang C, Liu D, Masuya D, Nakashima T, Kameyama K, Ishikawa S, Ueno M, Haba R and Yokomise H: Clinical application of biological markers for treatments of resectable non-small-cell lung cancers. Br J Cancer 92: 1231-1239, 2005 .

3. Weir B, Zhao X and Meyerson M: Somatic alterations in the human cancer genome. Cancer Cell 6: 433-438, 2004.

4. Imoto H, Osaki T, Taga S, Ohgami A, Ichiyoshi Y and Yasumoto K: Vascular endothelial growth factor expression in non-small-cell lung cancer: prognostic significance in squamous cell carcinoma. J Thorac Cardiovasc Surg 115: 1007-1014, 1998.

5. Adachi M, Taki T, Konishi T, Huang C, Higashiyama M and Miyake M: Novel staging protocol for non-small-cell lung cancers according to MRP-1/CD9 and KAI1/CD82 gene expression. J Clin Oncol 16: 1397-1406, 1998.

6. Katoh M: Expression and regulation of WNT1 in human cancer: up-regulation of WNT1 by beta-estradiol in MCF-7 cells. Int J Oncol 22: 209-212, 2003.

7. Chen G, Shukeir N, Potti A, Sircar K, Aprikian A, Goltzman D and Rabbani SA: Up-regulation of Wnt-1 and $\beta$-catenin production in patients with advanced metastatic prostate carcinoma: potential pathogenetic and prognostic implications. Cancer 101: 1345-1356, 2004.

8. Zhang WM, Lo Muzio L, Rubini C and Yan G: Effect of WNT-1 on beta-catenin expression and its relation to $\mathrm{Ki}-67$ and tumor differentiation in oral squamous cell carcinoma. Oncol Rep 13: 1095-1099, 2005.

9. Huang C, Liu D, Nakano J, Ishikawa S, Kontani K, Yokomise H and Ueno M: Wnt5a expression is associated with the tumor proliferation and the stromal vascular endothelial growth factor-an expression in non-small-cell lung cancer. J Clin Oncol 23: 8765-8773, 2005.

10. Herzlinger D, Qiao J, Cohen D, Ramakrishna N and Brown AM: Induction of kidney epithelial morphogenesis by cells expressing Wnt-1. Dev Biol 166: 815-818, 1994.
11. Dale TC: Signal transduction by the Wnt family of ligands. Biochem J 329: 209-223, 1998.

12. Labbe E, Lock L, Letamendia A, Gorska AE, Gryfe R, Gallinger S, Moses HL and Attisano L: Transcriptional cooperation between the transforming growth factor-beta and Wnt pathways in mammary and intestinal tumorigenesis. Cancer Res 67: 75-84, 2007.

13. Huang C, Liu D, Masuya D, Kameyama K, Nakashima T, Yokomise $\mathrm{H}$, Ueno $\mathrm{M}$ and Miyake $\mathrm{M}$ : MRP-1/CD9 gene transduction downregulates Wnt signal pathways. Oncogene 23: 7475-7483, 2004.

14. He TC, Sparks AB, Rago C, Hermeking H, Zawel L, da Costa LT, Morin PJ, Vogelstein B and Kinzler KW: Identification of c-MYC as a target of the APC pathway. Science 281: 1509-1512, 1998.

15. Scagliotti GV, Micela M, Gubetta L, Leonardo E, Cappia S, Borasio P and Pozzi E: Prognostic significance of Ki67 labelling in resected non small cell lung cancer. Eur J Cancer 29: 363-365, 1993.

16. Miller JR, Hocking AM, Brown JD and Moon RT: Mechanism and function of signal transduction by the Wnt/beta-catenin and Wnt/Ca ${ }^{2+}$ pathways. Oncogene 18: 7860-7872, 1999.

17. Turashvili G, Bouchal J, Burkadze G and Kolar Z: Wnt signaling pathway in mammary gland development and carcinogenesis. Pathobiology 73: 213-223, 2006.

18. Mizushima T, Nakagawa H, Kamberov YG, Wilder EL, Klein PS and Rustgi AK: Wnt-1 but not epidermal growth factor induced ß-catenin/T-cell factor-dependent transcription in esophageal cancer cells. Cancer Res 62: 277-282, 2002.

19. Korinek V, Barker N, Morin PJ, van Wichen D, de Weger R, Kinzler KW, Vogelstein B and Clevers H: Constitutive transcriptional activation by a ß-catenin-Tcf complex in APC-/ - colon carcinoma. Science 275: 1784-1787, 1997.

20. Lo Muzio L, Pannone G, Staibano S, Mignogna MD, Grieco M, Ramires P, Romito AM, De Rosa G and Piattelli A: WNT-1 expression in basal cell carcinoma of head and neck. An immunohistochemical and confocal study with regard to the intracellular distribution of beta-catenin. Anticancer Res 22: 565-576, 2002.

21. Hirsch C, Campano LM, Wohrle S and Hecht A: Canonical Wnt signaling transiently stimulates proliferation and enhances neurogenesis in neonatal neural progenitor cultures. Exp Cell Res 313: 572-587, 2007.

22. Cappellen D, Schlange T, Bauer M, Maurer F and Hynes NE: Novel c-MYC target genes mediate differential effects on cell proliferation and migration. EMBO Rep 8: 70-76, 2007.

23. Kim J, You L, Xu Z, Kuchenbecker K, Raz D, He B and Jablons D: Wnt inhibitory factor inhibits lung cancer cell growth. J Thorac Cardiovasc Surg 133: 733-737, 2007.

24. Obaya AJ, Mateyak MK and Sedivy JM: Mysterious liaisons: the relationship between c-Myc and the cell cycle. Oncogene 18: 2934-2941, 1999.

25. Dang CV, Resar LM, Emison E, Kim S, Li Q, Prescott JE, Wonsey D and Zeller K: Function of the c-Myc oncogenic transcription factor. Exp Cell Res 253: 63-77, 1999.

26. Zajac-Kaye M: Myc oncogene: a key component in cell cycle regulation and its implication for lung cancer. Lung Cancer 34: S43-S46, 2001.

27. Akie K, Dosaka-Akita H, Murakami A and Kawakami Y: A combination treatment of c-myc antisense DNA with all-transretinoic acid inhibits cell proliferation by downregulating c-myc expression in small cell lung cancer. Antisense Nucleic Acid Drug Dev 10: 243-249, 2000.

28. D'Agnano I, Valentini A, Gatti G, Chersi A and Felsani A: Oligopeptides impairing the Myc-Max heterodimerization inhibit lung cancer cell proliferation by reducing Myc transcriptional activity. J Cell Physiol 210: 72-80, 2007.

29. Richardson GE and Johnson BE: The biology of lung cancer. Semin Oncol 20: 105-127, 1993.

30. Broers JL, Viallet J, Jensen SM, Pass H, Travis WD, Minna JD and Linnoila RI: Expression of c-myc in progenitor cells of the bronchopulmonary epithelium and in a large number of non-small cell lung cancers. Am J Respir Cell Mol Biol 9: 33-43, 1993.

31. Volm M and Koomagi R: Prognostic relevance of c-Myc and caspase- 3 for patients with non-small cell lung cancer. Oncol Rep 7: 95-98, 2000.

32. Geisler JP, Geisler HE, Manahan KJ, Miller GA, Wiemann MC, Zhou Z and Crabtree W: Nuclear and cytoplasmic c-myc staining in endometrial carcinoma and their relationship to survival. Int $\mathbf{J}$ Gynecol Cancer 14: 133-137, 2004. 
33. Yang G, Timme TL, Frolov A, Wheeler TM and Thompson TC: Combined c-Myc and caveolin- 1 expression in human prostate carcinoma predicts prostate carcinoma progression. Cancer 103: 1186-1194, 2005.

34. Kubokura H, Tenjin T, Akiyama H, Koizumi K, Nishimura H, Yamamoto $\mathrm{M}$ and Tanaka S. Relations of the c-myc gene and chromosme 8 in non-small cell lung cancer: analysis by fluorescence in situ hybridization. Ann Thorac Cardiovasc Surg 7: 197-203, 2001.

35. Bondi J, Bukholm G, Nesland JM and Bukholm IR: Expression of non-membranous beta-catenin and gamma-catenin, c-Myc and cyclin D1 in relation to patient outcome in human colon adenocarcinomas. APMIS 112: 49-56, 2004.

36. Ozaki S, Ikeda S, Ishizaki Y, Kurihara T, Tokumoto N, Iseki M, Arihiro K, Kataoka T, Okajima M and Asahara T: Alterations and correlations of the components in the Wnt signaling pathway and its target genes in breast cancer. Oncol Rep 14: 1437-1443, 2005.
37. Bienz $M$ and Clevers H: Linking colorectal cancer to Wnt signaling. Cell 103: 311-320, 2000.

38. Ueda M, Gemmill RM, West J, Winn R, Sugita M, Tanaka N, Ueki $M$ and Drabkin HA: Mutations of the beta- and gammacatenin genes are uncommon in human lung, breast, kidney, cervical and ovarian carcinomas. Br J Cancer 85: 64-68, 2001.

39. Kotsinas A, Evangelou K, Zacharatos P, Kittas C and Gorgoulis VG: Proliferation, but not apoptosis, is associated with distinct beta-catenin expression patterns in non-small-cell lung carcinomas: relationship with adenomatous polyposis coli and $\mathrm{G}_{1}$-to S-phase cell-cycle regulators. Am J Pathol 161: 1619-1634, 2002.

40. Faivre EJ and Lange CA: Progesterone receptors upregulate Wnt-1 to induce epidermal growth factor receptor transactivation and c-Src-dependent sustained activation of Erk1/2 mitogenactivated protein kinase in breast cancer cells. Mol Cell Biol 27: 466-480, 2007. 